\title{
Response to the Call: Has This Close Call Been a Wake Up Call?
}

\author{
Mary Furey \\ Memorial University of Newfoundland \\ Daphne Rixon \\ St. Mary's University
}

\begin{abstract}
This paper uses a case study of a 911 service outage to explore the extent to which telecommunications companies (Telco's) and governments learn from serious incidents and close calls. The study takes a longitudinal approach to identify initial company and government reactions and then revisits key government stakeholders through interviews and documentary reviews to discern whether any lessons were learned. The research found that although initially the telecommunications company involved in the outage and the local levels of government expressed concern and indicated they would introduce changes to ensure such an incident would not occur again, after more than a decade, there were no changes in government requirements for back-up and disaster recover standards. Clearly, this close call was not a wake-up call.
\end{abstract}

Keywords : telecommunications companies, Telco's, 911 service

\section{INTRODUCTION}

In October 2006 Bell Aliant, the primary provider of telephone and internet services in the Province of Newfoundland and Labrador, Canada, experienced a small fire in a building which housed both its main system and back-up system. As a result, both systems were disabled. Consequently, the capital city, St. John's was left without telephone, cell phone, internet service and most incredibly without '911' emergency service. This presented a potentially dangerous situation whereby over 150,000 citizens were unable to call the fire department or ambulance service (Rixon and Furey, 2009).

The purpose of this paper is to examine long-term learning by key stakeholders impacted by this incident. The study is comprised of two phases. Phase 1 was conducted in 2007 and examined the response by stakeholders (Telco's and government) immediately after the incident in 2006. Phase 2 was completed in 2018 and focused on whether the federal and provincial government departments and their respective agencies have learned from this incident as demonstrated through more stringent back-up standards. The 2018 study examines only the federal and provincial government learning since they have the power to mandate that the telecommunications industry implement more robust systems backup and disaster recovery mechanisms to ensure resiliency of the 911 system. In other words, did this close call serve (Rixon and Furey, 2009) as a wake-up call to government departments and agencies that are accountable for the provision of 911 service? Did the various levels of governments responsible for 911 service learn from this incident? 
This outage was far from an isolated incident. Indeed, for the time period 2004 to 2007, a total of 218 service outages were reported (Rixon and Furey, 2009). Of the 218 service outages reported, the majority $157(72.02 \%)$ were less than seven hours duration. That being said, an outage of even one hour could have serious implications in a situation where alternative forms of communication such as cellular telephones and internet services are impacted. Furthermore, the research found there were $14(6.42 \%)$ outages that had duration of 1-2 days (Rixon and Furey, 2011). Since this initial 2006 incident there have been a wide array of 911 service outages throughout Canada such as those identified in Appendix 1.

It is important to conduct this study since there is a paucity of research focusing on learning from crisis situations by government agencies and departments. Despite the considerable body of literature on organizational learning in companies as it relates to disasters, there is a little research on long-lasting changes made by government agencies and departments to their standards as a result of experiencing a disaster, serious incident or a close call. Although prior studies have examined close calls, they have concentrated primarily on situations involving commercial enterprises. Even those such as the Challenger that were the responsibility of government organizations, they did not entail the provision of essential services to citizens. This paper adds to the research on organizational learning from close calls because it focuses on the impediments to learning by government departments and government agencies.

\section{CONTEXT}

This section provides an overview of the telecommunications industry in Canada. The federal government of Canada regulates the telecommunications industry to ensure the provision of essential telecommunications services to citizens. The seventy-eight telecommunication companies in Canada are regulated by the Canadian Radio-television and Telecommunications Commission (CRTC), an agency of the federal government. The CRTC reports to Parliament through the Minister of Canadian Heritage. The Canadian Heritage Department is a large, diverse department that is responsible for five departmental agencies, nine crown corporations, the Public Service Commission, the Public Service Labour Relations Board and the Public Service Staffing Tribunal [14] (Rixon and Furey, 2011). In addition to the Federal government, as illustrated in Table 1, there are several government departments and agencies that are responsible for the delivery of 911 service in Canada.

TABLE 1

ROLES AND RESPONSIBILITIES FOR 911 SERVICE

\begin{tabular}{|l|l|}
\hline Government Organization & \multicolumn{1}{c|}{ Responsibilities } \\
\hline Federal Government of Canada & $\begin{array}{l}\text { Responsible for oversight of all government departments and } \\
\text { agencies. The Federal government department charged with } \\
\text { oversight and regulation of the telecommunications sector is } \\
\text { the Department of Heritage. }\end{array}$ \\
\hline $\begin{array}{l}\text { Department of Heritage (Federal } \\
\text { Government) }\end{array}$ & $\begin{array}{l}\text { The Department of Heritage has delegated responsibility for } \\
\text { the telecommunications sector to a Federal Crown agency, } \\
\text { Canadian Radio-television and Telecommunications } \\
\text { Commission (CRTC). The Department of Heritage is also } \\
\text { responsible for a wide array of cultural issues in addition to } \\
\text { telecommunications. }\end{array}$ \\
\hline $\begin{array}{l}\text { Canadian Radio-television and } \\
\text { Telecommunications Commission } \\
\text { (CRTC) }\end{array}$ & $\begin{array}{l}\text { The Commission consists of a Chairperson, two Vice- } \\
\text { Chairpersons, and up to 10 regional Commissioners. The } \\
\text { CRTC is an administrative tribunal that regulates and } \\
\text { supervises broadcasting and telecommunications in the public } \\
\text { interest. https://crtc.gc.ca/eng/home-accueil.htm accessed } \\
\text { July 20,2020 }\end{array}$ \\
\hline
\end{tabular}




\begin{tabular}{|l|l|}
\hline $\begin{array}{l}\text { Government of Newfoundland \& } \\
\text { Labrador }\end{array}$ & $\begin{array}{l}\text { Responsible for provision of 911 service to citizens. The } \\
\text { Provincial government has delegated responsibility to the } \\
\text { Department of Municipal Affairs. }\end{array}$ \\
\hline $\begin{array}{l}\text { Department of Municipal Affairs } \\
\text { (Provincial Government) }\end{array}$ & $\begin{array}{l}\text { The Department of Municipal Affairs has delegated } \\
\text { responsibility for 911 service delivery to 911NL, which is a } \\
\text { crown agency. }\end{array}$ \\
\hline $911 \mathrm{NL}$ & $\begin{array}{l}\text { Emergency 911 service in Newfoundland is the responsibility } \\
\text { of NL911, a not-for-profit corporation established through } \\
\text { the Emergency 911 Act. It is governed by a board of } \\
\text { directors. }\end{array}$ \\
\hline
\end{tabular}

At the time of the 2006 outage, the City of St. John's and all other towns in the province of Newfoundland and Labrador were responsible for the provision of 911 services. However, by 2015, 911 coverage for all regions of the province became the responsibility of the Provincial Government through a new agency, NL911 (Power, 2014).

It should also be noted that Canada's CRTC regulatory regime is not unique. For example, there are similar systems in the United Kingdom, United States and Australia. It should also be noted that Canada's CRTC regulatory regime is not unique. For example, there are similar systems in the United Kingdom, United States and Australia.

In the United Kingom the Body of European Regulators for Electronic Communications (BEREC), is an independent European Union (EU) body consisting of the National Regulatory Authorities (NRA) for the electronic communications sector from the Member states of the European Union, candidate countries and European Economic Area states, the EFTA Surveillance Authority and the European Commission as observers, and facilitates the consistent application of the telecommunication rules throughout the European Union (Memoriam of Understanding, 2020). In Australia the Australian Communications and Media Authority (ACMA) is an Australian Government statutory authority that regulates communications and media services within the Communications portfolio (Who we are, 2020). Similarly, in the United States the Federal Communications Commission (FCC) regulates interstate and international communications by radio, television, wire, satellite and cable in all 50 states, the District of Columbia and U.S. territories. An independent U.S. government agency overseen by Congress, the commission is the United States' primary authority for communications law, regulation and technological innovation (What we do, 2020).

To fully appreciate the context of this study, it is important to outline the technical industry protocols and best practices for systems back-up and disaster recover. The standards for systems back-up and disaster recovery have been established by the International Standards Organization. Within the telecommunications sector, the International Electrotechnical Commission (IEC) has developed standards for many aspects of telecommunications. Standards relating to systems back-up and recovery protocols since establishment of these protocols is a key factor in ensuring the continuity and reliability of telecommunications services (Rixon and Furey, 2011).

The IEC (17799) sections $(9.1 .4,9.2 .1$, and 9.2.3) state that fall back equipment and back-up media should be situated at a safe distance to avoid damage from a disaster affecting the main site; controls should be adopted to minimize the risk of potential physical threats such as theft and fire; and areas that sensitive or critical systems should consider several items including use of alternative routings and/or transmission media providing appropriate security as well as the use of fibre optic cabling (Rixon and Furey, 2011). 


\section{LITERATURE REVIEW}

Our literature review concentrated on organizational learning as a result of a disaster, serious incident or close call. While much of the literature focused on how companies learned from crisis and near misses, some researchers examined the learning outcomes at the individual employee level rather than the organizational level of learning. For example, Carroll (1998) studied self-analysis of operating problems among employees at nuclear power plants and chemical process plants and found that employees are expected to learn from precursors and near-misses, rather than exclusively by trial-and-error. Similarly, Morris and Moore's (2000) study of learning from close calls at an aviation field found that individuals were more likely to learn when they reacted to an event as a narrowly averted collision with upwarddirected, self-focused counter-factual thoughts.

Instead of relying on precursors and close calls as experienced by individuals, another strand of literature examines how experience with previous disasters impacts learning and ultimately how organizations' respond to subsequent disasters. For example, Madsen's (2009) study of coal mines revealed that organizations reduce their likelihood of future disaster through direct experience with disaster, direct experience with minor accidents, and vicarious experience with disaster.

There is also a wide array of studies on crisis management in response to disasters. In their case study of Cantor Fitzgerald's (CFs) effective response to the 9/11 crisis, Seeger, Ulmer, Novak and Sellnow (2006) described the CEO's crisis management response which included his public commitment to rebuild the organization, his maintenance of a discourse of renewal, and his reiteration of the values of the organization (e.g., CF's commitment to the community). This initial communication provides insight into how the organization intends to respond and learn from the crisis. Other studies highlighted how learning, crisis management and performance were interrelated. For example, Zehir and Yavuz (2014) found in their examination of Turkish companies' responses to several economic crises that three factors (learning, crisis management, and performance) were correlated, and that learning capability significantly affected crisis preparedness and organizational performance.

Our literature review found several studies on frameworks that organizations employ to effectively learn from a crisis. For example, Wang (2008) proposes a learning model that starts with Crisis Unlearning/Unfreezing as the first step whereby organizations should abandon old ideas and ineffective programs and begin to embrace new ideas. The next steps in crisis management include Knowledge Acquisition and Diffusion, Knowledge Utilization and Organizational Memory. In other words, detailed records of the organization's crisis solutions are kept for future reference. Finally, the organization goes through Change/Refreeze to adapt to, and cope with, the new organizational environment. This entails organizations changing their structure, contingency plans, and communication protocols after a crisis.

In their in-depth examination of organizational learning, Lipshitz, Popper and Friendman (2002), focused on learning in versus by organizations. Their proposed conceptual framework incorporates the five facets of organizational learning: structural, cultural, psychological, policy, and contextual facets.

In contrast to learning subsequent to a crisis, other researchers focus on crisis preparedness as a mechanism to mitigate the negative impact of a disaster. While it is not realistic to assume that all disaster events can be prevented, Baker et al (2004) have shown how their impact can be reduced through preparedness, specific implementation of survivable network architecture, and pre-developed processes for their recovery. The researchers have developed four fundamental aspects for disaster preparedness and recovery (also known as “the four P's"): plans, processes, people, and procedures.

While most of the literature reviewed focuses on how companies and their employees learn from disasters, there is a limited body of literature that examines how governments learn from disasters, serious incidents and close calls. Elliott (2009) explores the failure of the UK government organization, Child Protective Services, to learn from the death of two children in its care. According to Elliott (2009), these crises occurred because there was a failure to bridge the gap between policy and practice, and particularly a failure to disseminate knowledge effectively following a public inquiry. The author suggests that those conducting the public inquiry on crises should consult with experts that could help translate knowledge into 
practice via policy change, and they should recognize and address barriers and facilitators to organizational learning.

Furthermore, these studies concentrate on the causes of governments' poor response in a crisis situation as opposed to identifying how they learned from the various incidents. Veil and Husted (2010) examined best practices regarding risk and crisis management as illustrated by the American Red Cross's ineffective response to Hurricane Katrina. This research focused on the Red Cross's flawed and ineffective communication network, lack of adequate partnerships and lack of planning for their crisis response.

Elliott and Macpherson (2010) examined the barriers to organizational learning with respect to the 2007 flooding in the UK and how the Gloucestershire County Council (GCC) responded to the crisis. The authors found the GCC failed to cope effectively with this crisis. For example, the GCC failed to consult with agencies when developing emergency plans and to communicate effectively with staff, communities, and partner authorities. The authors reasoned that the failure in the context and infrastructure, institutional norms (i.e., responsibilities, procedures, and regulations), tools and technology, and social association and levels of interactions all contributed to the lack of response and organizational change during and after the flooding crisis.

Despite the history of many disasters and serious incidents, it appears there are a wide array of barriers that limit the ability of organizations, including governments, to learn from these situations: (1) rigid core beliefs, (2) poor communication, (3) denial, centrality of expertise, and the disregard of outsiders, (4) peripheral inquiry and decoy phenomenon, (5) cognitive narrowing and fixation, (6) maladaptation threat minimization and environmental shifts, (7) lack of corporate responsibility, and (8) focus on single-loop learning (Smith and Elliott, 2007).

A comprehensive approach to organizational learning after crisis was proposed by Kayes and Yoon (2016). They contend there are four stages of organizational learning post crisis: (1) establishing a culture of resilience, (2) surfacing and responding to precursor events, (3) learning through crisis, and (4) sustaining and renewing learning. According to the authors, the first step that organizations need to take to learn from crises and implement positive changes is to create a culture that values learning, new ideas, and open communication, and holds its employees accountable in embracing these values. If the organization is successful at establishing this culture then it will likely move on to the second stage where members will take action to identify and address potential vulnerabilities before they escalate into crises (e.g., by developing a crisis management system). If any crises or problems arise, then organizations are equipped to handle them and learn from them in the third stage. Finally, organizations typically reach the final stage where they should focus on maintaining their new culture and the positive organizational changes that they made.

As illustrated through this literature review, most of the research on organizational learning from a disaster and close calls concentrate on companies and their employees. Many studies review the causes of various crisis and provide recommendations regarding corrective and preventative action. However, there are virtually no longitudinal studies focused on the government organizations to ascertain the extent to which they actually learned from a prior crisis or close call. Furthermore, there is a paucity of literature on learning by government departments and government agencies that are responsible for the oversight and regulation of the provision of essential 911 emergency services.

\section{METHODOLOGY}

We employ a case study methodology for this research that is comprised of semi-structured interviews and a documentary review of the CRTC legislation and service standard requirements for Telco's as well as a Request for Proposal for telecommunications services issued by the Government of Newfoundland and Labrador. The study is comprised of two phases as described in the following sections.

\section{Phase 1: Research}

The initial phase of our study was conducted in 2007 (Rixon and Furey, 2009, 2011). In the first phase, four respondents holding senior management positions at the Government of Newfoundland, City of St. 
John's, Bell Aliant, and Rogers Communications were interviewed. In addition, we conducted a documentary review of the CRTC service standards and telecommunications legislation. Bell Aliant as owner of the communication infrastructure was responsible for appropriate service continuity, disaster recovery, and systems back up. Rogers Communications simply provided a service based on Bell Aliant's infrastructure and the City of St. John's worked on the basis of the protocols established by the provincial government of Newfoundland. As the regulator, the CRTC had a key role to play in ensuring adherence to industry standards related to systems back-up and recovery.

\section{Phase 2: Research}

The second phase of our study was conducted in 2018 and focused only on the Federal and Provincial governments since they had the authority and power to change reliability and resiliency protocols and to require Telco's to adhere to these standards. The Federal Government of Canada, through the CRTC has the authority to mandate standards for service continuity, disaster recovery, and systems back up. Similarly, the Provincial Government of Newfoundland and Labrador had the power and authority to request standards for service continuity, disaster recovery, and back up when they are contracting for telecommunications services. In Phase 2, we interviewed two respondents from the Provincial Government department that has responsibility for telecommunications services as well as a respondent from the Provincial Government Agency (NL911), that is responsible for the delivery of 911 service throughout the province. Respondents are denoted as PG1, PG2 and NL911. In Phase 2, we also conducted a documentary review of the CRTC's current standards for Telco's as well as the results of their industry consultation regarding 911 service. We also reviewed the provincial government's 2018 request for proposal for telecommunications services. Finally, we conducted an extensive documentary review of the websites of the provincial government, NL911 and the CRTC. In addition to the documentary reviews, in-depth semi-structured interviews were conducted with two officials of the Provincial Government of Newfoundland and Labrador and one interview was undertaken with a respondent from NL911.

The case study methodology is ideally suited to the stated objectives of this study. Yin (1994) defines case studies as a multi-faceted research strategy which typically involves an in-depth examination of one organization, situation or community. Furthermore, face-to-face surveys are useful to examine complex issues, allow for maximum degree of probing, yield a better response rate, provide flexibility over question content and facilitate clarification of questions and terminology (Singleton and Straits, 2002).

While case studies yield greater realism than quantitative methodologies, it must be recognized that they are time consuming, their findings cannot be generalized and their lack of rigorous control compromises validity (Bennett, 1991; Hill, 1993). Although all the disadvantages cannot be mitigated, a case study methodology is the most appropriate for this research due to the complex nature of the research questions and the need to solicit in-depth feedback from a small number of respondents (Rixon and Furey, 2011).

\section{RESEARCH FINDINGS: DISCUSSION AND ANALYSIS}

The research findings are set out in two sections. The first section presents key findings from the initial phase of the study which was conducted in 2007. The second section presents the findings from the 2018 research.

\section{Section 1: Findings From the 2007 Study}

Table 2 depicts the main research findings concerning the existing standards of the various organizations involved in this incident along with the gaps or weaknesses. 


\section{TABLE 2.0 \\ COMPARISON OF STAKEHOLDER ACCOUNTABILITY STANDARDS, GAPS AND RESPONSES}

\begin{tabular}{|l|l|l|l|}
\hline Organization & Standard & Accountability Gap & 2007 Response \\
\hline CRTC & $\begin{array}{l}\text { Mandatory } \\
\text { quality of service } \\
\text { standards for } \\
\text { both retail and } \\
\text { commercial } \\
\text { customers }\end{array}$ & $\begin{array}{l}\text { Quality of service standards do not } \\
\text { appear to set the bar high enough; } \\
\text { The CRTC does not require } \\
\text { adoption of a key industry standard } \\
\text { for systems back-up. }\end{array}$ & $\begin{array}{l}\text { No changes in practice re } \\
\text { quality of service standards, } \\
\text { disaster recovery or back-up } \\
\text { protocols }\end{array}$ \\
\hline City of St. John's & $\begin{array}{l}\text { Continuity of } \\
\text { essential } \\
\text { emergency } \\
\text { services (911) for } \\
\text { citizens }\end{array}$ & $\begin{array}{l}\text { Previous disaster recovery plans and } \\
\text { emergency preparedness protocols } \\
\text { did not appear to include provisions } \\
\text { for loss of telecommunications; } \\
\text { Contract with Bell Aliant did not } \\
\text { include a requirement for } \\
\text { telecommunications backup and } \\
\text { disaster recovery plan }\end{array}$ & $\begin{array}{l}\text { Requested independent } \\
\text { review of the cause of the } \\
\text { outage; include telco outage } \\
\text { in emergency testing taken } \\
\text { one week after this incident }\end{array}$ \\
\hline $\begin{array}{l}\text { Government of } \\
\text { Newfoundland }\end{array}$ & $\begin{array}{l}\text { Responsible for } \\
\text { emergency } \\
\text { preparedness for } \\
\text { citizens }\end{array}$ & $\begin{array}{l}\text { Previous disaster recovery plans and } \\
\text { emergency preparedness protocols } \\
\text { did not appear to include provisions } \\
\text { for loss of telecommunications; } \\
\text { Contract with Bell Aliant did not } \\
\text { include a requirement for } \\
\text { telecommunications backup and } \\
\text { disaster recovery plan }\end{array}$ & $\begin{array}{l}\text { Indicated future contracts } \\
\text { would require backup and } \\
\text { disaster recovery; Initiated } \\
\text { new fibre optic deal with } \\
\text { alternate providers }\end{array}$ \\
\hline $\begin{array}{l}\text { Rogers } \\
\text { Communications }\end{array}$ & $\begin{array}{l}\text { Continuity of } \\
\text { telephone and } \\
\text { internet service } \\
\text { to } \\
\text { customers }\end{array}$ & $\begin{array}{l}\text { Contract with Bell Aliant did not } \\
\text { include a requirement for } \\
\text { telecommunications backup and } \\
\text { disaster recover plan }\end{array}$ & $\begin{array}{l}\text { Participating in the new } \\
\text { fibre optic deal } \\
\text { with government }\end{array}$ \\
\hline
\end{tabular}

Sources: semi-structured interviews conducted in 2007 and CRTC Website

\section{Section 2: Findings From 2018 Research Study}

CRTC: Changes Since 2007 Regarding 911 Service

We commenced the 2018 study by identifying changes in the CRTC's regulations for 911 service delivery. Our documentary review of the CRTC's service standards revealed that they commenced a consultation process in 2015 regarding 911 service delivery. The documents do not refer to recent outages as the impetus for their study of the regulations governing 911 service. Some of the relevant information requested by the CRTC's 2015 notice of consultation included the following: (CRTC, 2015 - 305):

Description of telecommunication services provided as part of the 9-1-1 network, resiliency and reliability of the network, and how and to whom 9-1-1 network outages are monitored and reported, adherence to engineering principles and industry best practices, vulnerability assessments that the company had undertaken, as well as any actions taken to 
address the vulnerabilities identified. Sample of a 9-1-1 agreement between the telephone provider and the municipal/territorial/ provincial government the company services identify all major 9-1-1 network outages that occurred in the past five years and describe all remedial action taken to restore the network in those instances. Detailed 5-year plan of the measures the company will take to increase the reliability and resiliency of 9-1-1 network, including the proposed timelines and costs associated with the implementation of such measures (CRTC - 2015-305). Measures taken to ensure the uninterrupted operation of their 9-1-1 network in the event of a power outage, how they monitor the quality of operation, and if, and how, the company notifies other telephone providers and PSAPs of any network outages.

As part of the CRTC's consultation process, the following responses were provided by the Canadian Telco's.

\section{Is It appropriate for the Commission to Impose Regulatory Measures Regarding the Reliability and Resiliency of the 9-1-1 Networks?}

Telco Responses: The telecommunication's companies argued that regulatory measures were not necessary since the current 9-1-1 network is reliable and resilient. However, the Public Interest Advocacy Centers (PIAC) and PSAP's maintained that the Commission should establish regulatory measures to ensure consistency in the reliability and resiliency of 9-1-1 networks across the country (CRTC 2016-165).

CRTC Decisions: Based on these comments, the Commission decided that the imposition of regulatory measures was not necessary. The CRTC concluded that the 9-1-1 network is resilient and reliable and that very few small-scale, and no large-scale, 9-1-1 outages have occurred. However, the Commission did impose the following obligation, pursuant to The Telecommunications Act, Section 24, on all 9-1-1 network providers:

\section{"9-1-1 network providers must take all reasonable measures to ensure that their 9-1-1 networks as defined are reliable and resilient to the maximum extent feasible."}

To meet this obligation, the Commission suggests that network providers follow 9-1-1 network design principles, operation maintenance practices, and implement contingency plans for disaster or outage recovery (CRTC 2016-165).

\section{Are 9-1-1 Service Outage Notifications Necessary?}

Teleco Responses: Currently, there are industry established notification guidelines but none that are imposed by the Commission. The 9-1-1 network stakeholders have conflicted opinions about whether the Commission should impose notification guidelines. For example, three submissions indicated that the Commission should impose such guidelines, while two claimed that it is not necessary (CRTC 2016-165).

CRTC Decisions: Based on the position of parties, the CRTC concluded that some consistency should be established with respect to the type of outage that triggers a notification, the parties that are notified, and the time frame in which to provide notifications. The Commission has introduced a requirement that notifications be made to the parties affected, especially those involved in restoring the service, within 30 minutes of discovering the outage. Additionally, the Commission requires that 9-1-1 networks notify telephone providers and PSAPs of outages, service restorations, and dropped 9-1-1 calls so that PSAPs can follow-up with callers. However, the Commission does not require the parties to notify of such outages since the Commission is not involved in restoring the 9-1-1 service. Furthermore, the Commission encourages, but does not require, PSAPs to notify network and telephone providers of PSAP outages (CRTC 2016- 165). 


\section{Should the Commission Implement Quality of Service Standards or Service Level Agreements?}

Teleco Responses: All but two submissions argued that the implementation of quality of service standards is not necessary as there is no evidence to indicate deficiencies in the network that would warrant the implementation of such standards (CRTC 2016-165).

CRTC Decisions: Based on these responses, the Commission has decided not to implement quality of service standards. The CRTC concluded that the current 9-1-1 networks is reliable and resilient, and that no quality of standards need to be implemented at this time (CRTC 2016-165). In addition to the requirements outlined above, the CRTC introduced a requirement that all 9-1-1 network providers file an annual report on network outages including the date, duration, and cause of outage. The Commission also encourages network providers to share information and collaborate with one another, but it does not require the establishment of a 9-1-1 network provider forum (CRTC 2016-165).

\section{DISCUSSION AND ANALYSIS: CRTC}

The CRTC decisions based on the previous three questions were somewhat lax. For example, with respect to the possible imposition of regulatory measures for reliability and resiliency of the 911 network, not surprisingly the Telco's argued this was not necessary since they already had a high quality of service. The CRTC concurred with the Telco's and mandated only very general guidelines that Telco's take reasonable measures to ensure continuity of 911 service. In this instance the CRTC as the regulator actually had the power and authority to mandate specific standards related to backup and disaster recovery. However, they left it to the Telco's to determine the standards.

In relation to the second question on notification of 911 service outage, the CRTC decided to require that the Telco's notify those impacted by the outage within 30 minutes. However, the CRTC determined it was not necessary for Telco's to advise CRTC. This appears to be a situation where the CRTC missed an opportunity to hold Telco's to a higher degree of accountability by requiring them to report 911 service outages immediately. Consequently, there is no formal mechanism for the CRTC to monitor 911 service outages.

With respect to the third question around the quality of service standards the CRTC agreed with that Telco's that since the 911 system is reliable and resilient the implementation of such standards are not required. Clearly, given the extensive documented history of 911 service outages, the system is not as reliable and resilient as claimed by the Telco's. It is concerning that the CRTC did not acknowledge these frequent outages in their report and decisions. Again, this is an area where the CRTC could have mandated a higher level of 911 service but opted not to impose such a service standard.

Finally, while the CRTC did not require Telco's to report service outages as they occur, the commission did implement a new requirement for 911 network providers to disclose in their annual reports all network outages including date, duration, and cause.

Overall, it is concerning that the CRTC relied heavily on the views of the Telco's when reviewing and updating standards. It may have been more beneficial and objective to have obtained an independent, third party opinion regarding the optimal level of back-up and disaster recovery.

\section{Government of Newfoundland and Labrador: Changes Since 2007 Regarding 911 Service}

The second part of our 2018 study involved a documentary review of the Provincial government's Request for Proposals (RFP) for telecommunications services issued in 2018 and semi-structured interviews with three respondents in the government department and agency that were responsible for the Newfoundland Provincial Government's telecommunications and delivery of 911 service. Two of the respondents indicated they were working in government at the time of the 911 outage in 2006. PG1stated that are there had been discussions shortly after the 2006 outage but that there was no specific action identified to prevent a similar outage in the future, but indicated there were measures taken with respect to enhancing broadband: 
"After the major outage a few years ago, implementing broadband was discussed, but was abandoned because of the cost of $\$ 800$ million. The provincial government partnered with Persona [a private cable company] to develop Atlantic Cable Facility (ACF). Government owns several sections but would now like to divest of its ownership in $A C F$."

With regard to future development PG1 stated that two initiatives were in progress: (1) to capitalize on radio systems such as the police use of the Motorola radio systems and (2) to issue a Request for Proposals (RFP) for cellular, landline and wide area network that bundles all government entities, crown corporations, and school boards into the same RFP. During the 2006 outage it was widely recognized that neither government nor Bell Aliant had envisioned a situation where landlines, cellphones and internet service would all be disrupted at the same time. This resulted in subsequent discussions regarding increased usage of two-way ratio systems.

In addition, respondent PG1 noted the following ongoing discussions:

"With respect to Fire and Emergency, the Federal Government, police are talking about a public safety network. There is a move a foot to capitalize on radio systems. Currently the police use the Motorola radio systems."

Although the NL911 agency was established several years after the 2006 outage, the organization is cognizant of the importance of implementing alternative arrangements. In referring to another more recent outage in the summer of 2018, the NL911 respondent explained:

"We don't currently utilize radios for 911 service. From a 911 perspective we need more radio and cell phone service. We put into place additional capabilities after last summer's outage. When there is a complete outage all agencies in St John's would physically go to the St John's Regional Fire Department. They would use radios to communicate to the other agencies."

While the creation of the NL911 agency was intended to provide a co-ordinated delivery of 911 service, this new approach did not eliminate all issues surrounding provincial responsibility. The NL911 respondent explained that government oversight and responsibility for telecommunications is a bit disjointed as reflected in the following remark:

"There is no direct communication or liaison between various government departments and the 911 office. The 911 office reports to the department of municipal affairs. They also have a fairly closely with the fire emergency services. Sometimes there is some interaction with the Department of Justice and Department of Health if they have any questions about 911."

Further evidence of a disjointed approach is reflected in the NL911 response regarding involvement in the Provincial Government's Request for Proposal for telecommunications services: "we were not involved in the main government RFP. Instead, NL911 has their own contract with Bell Aliant”.

The PG1 respondent concurred with this the characterization of the disjointed relationship between the provincial government and 911 as depicted in the respondent's description summarised in Table 3: 


\section{TABLE 3}

\section{RESPONSIBILITY FOR PROVINCIAL GOVERNMENT TELECOMMUNICATIONS AND 911 IN 2018}

\begin{tabular}{|l|l|}
\hline Service & Responsibility \\
\hline Cellular, landline and networks & Office of the Chief Information Officer \\
\hline Radio systems & Department of Justice and Public Safety \\
\hline $\begin{array}{l}\text { Telecommunications contract } \\
\text { administration }\end{array}$ & Department of Transportation and Works \\
\hline 911 Service Delivery & $\begin{array}{l}\text { NL911 (provincial government agency that } \\
\text { reports to Department of Municipal Affairs) }\end{array}$ \\
\hline
\end{tabular}

Source: Semi-structured interviews with provincial government, 2018

With respect to the RFP for telecommunications services, when asked if government requests certain criteria regarding backup and disaster recovery, the respondent stated:

"We ask vendors to describe what they have. We are not in a position to dictate, but if anything shocking came out, we would re-issue the RFP. We leave the requirements fairly open in the RFP. We ask bidders who respond to the RFP to describe how they are going to deal with back-up, outages, disaster and redundancy. I don't have a true telephony background."

The NL911 respondent described their approach for systems back-up and disaster recovery, the NL911 respondent offered the following explanation:

"NL911 has separate emergency phone service. There is redundancy in place if the line to the St. John's site goes down and can't take calls, we can then push all calls to the other office in Corner Brook [city in western Newfoundland]. We test the system annually to ensure business continuity. Bell Aliant also has a redundancy system in place."

In response to our question regarding how the Provincial Government could hold the telecommunications company accountable for service outages, the respondent from NL911 stated:

"We have no authority over Bell Aliant. The CRTC only has so much authority. If there is an outage Bell Aliant sends notification. Bell Aliant has a 911 contact person here that we can call if there is a major problem. After last year's outage [2017], Bell Aliant was required to prepare and report back to NL911 on the cause of the outage and how they were going to fix the problem so that it did not occur again in the future. Bell Aliant has advised that they now have a third line in place which is routed through the eastern United States. We don't currently utilize radios for 911 service. From a 911 perspective we need more radio and cell phone service."

The optics of telecommunications outages and responsibilities for these outages is clearly of importance to the NL911 agency as reflected in the following comment:

"We need to change the language for Bell Aliant as well as the police to be clear when issuing public service announcements at regarding 911. It should not be called a 911 outage rather it's a landline outage or cell phone outage." 


\section{Discussion and Analysis: Interviews}

The provincial government department's response that they do not have the authority to require Telco's to have a minimum level of standard such as criteria for continuity of service is surprising. As the issuer of the request for proposals (RFP) the government does indeed have the authority to request those vendors bidding on the contract to guarantee such a level of system reliability. It is likely that this was not included in the RFP because the Department did not have sufficient expertise to identify specific requirements as reflected in one respondent's admission that he did not have a background in telephony. Furthermore, NL911 appeared to rely on Bell Aliant to have the appropriate redundancy in place. As for the second backup line in another city, this would not necessarily be effective if there was province-wide outage.

The lack of inclusion of NL 911 agency in the provincial government's RFP process is also surprising. This is likely a result of the organizational structure for government telecommunications as illustrated in Table 3. The Chief Information Officer's (CIO's) Department is responsible for cell phone and landlines, but the RFP is actually issued by the Department of Works and Transportation. Meanwhile, the NL911 is an agency that reports to the Department of Municipal Affairs. The organizational structure is perhaps one of the contributing factors to the lack of input and coordination with respect to the identification of specific back-up and disaster recovery requirements in the government RFP for telecommunications services. Furthermore, despite indicating in 2007 that industry standards for backup and disaster covered would be included in future RFP's, our research found this was not the case. In fact, government did not include any specific industry standards in its RFP.

As illustrated in Figure 1, the telecommunications companies have a high level of knowledge about appropriate systems backup and recovery protocols. In comparison, the Federal and Provincial governments and their respective agencies have the formal power through legislation to regulate the provision of 911 service. As illustrated through this study, the provincial government department and agency responsible for the provision of 911 service do not appear to have a sufficient level of technical knowledge to implement effective regulatory control. In theory, the government should have ultimate power for the provision of essential 911 emergency service. However, in practical terms, government's lack of knowledge appears to have weakened their power. Indeed, both levels of government, Federal and Provincial, place a considerable degree of reliance on the opinions and proposals from the telecommunications companies. Consequently, the balance of both power and knowledge appears to be in favour of the telecommunications companies, not the government.

FIGURE 1

TELECOMMUNICATIONS \& GOVERNMENT: POWER AND KNOWLE

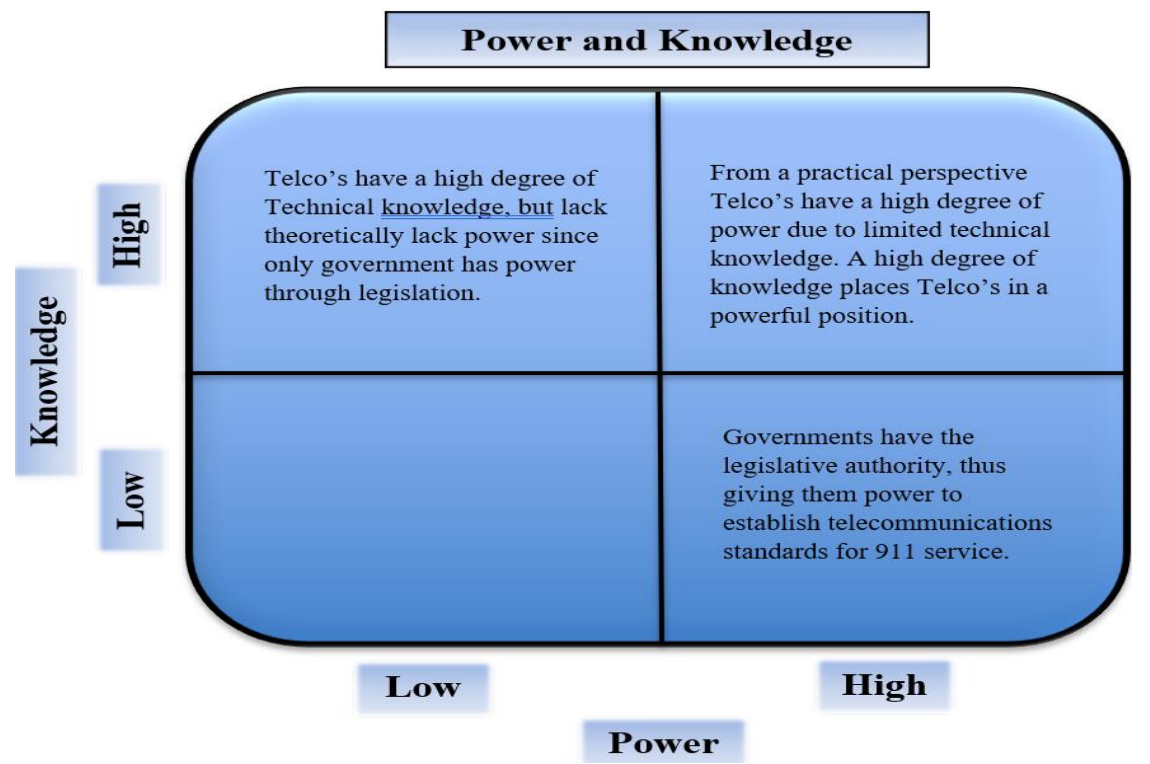


Overall, the various levels of government did not demonstrate they had learned from these potentially serious 911 service outages. When comparing the actions of the Federal and Provincial governments along with their respective departments and agencies, there is no evidence of learning over this period of time from 2006 - 2018. For example, when comparing our findings to Kayes \& Yoon's (2016) four stages of post crisis learning, there is no indication of progression through the four stages: : (1) establishing a culture of resilience, (2) surfacing and responding to precursor events, (3) learning through crisis, and (4) sustaining and renewing learning.

While the balance of power appears to rest with the regulated (Telco's) rather than with the regulators (governments), it could be argued that the multiple layers of federal and provincial departments and agencies make it very challenging environment to foster post crisis organizational learning. To achieve meaningful learning, the federal government, department of Heritage and CRTC as well as the Provincial government, department of Municipal Affairs and NL911 would ideally need to embark on a co-ordinated effort to learn from these incidents in their respective organizations. The delegation of responsibility from department to agencies, CRTC and NL911 further weakens accountability and thereby inhibits the creation of an organizational climate that fosters organizational learning.

\section{CONCLUSIONS}

This paper set out to examine long-term learning by government departments and agencies as a result of the 911 service outage that occurred in 2006 in St. John's, Newfoundland, Canada. Phase 1 of our research identified the key organizations involved in this service outage, the accepted industry standards and gaps in the adopted standards. The major objective of this paper was to investigate the responses of the regulator (CRTC) and the local governments to discern if major corrective action was taken as result of this near miss. We found local governments and Bell Aliant initially viewed this incident as a wake-up call and stated they would take various forms of corrective action to ensure this type of service outage did not occur again.

In Phase 2 of the study, our objective was to discern if there was any evidence of long-term learning by the two levels of government (provincial and federal) that have ultimate responsibility for 911 emergency service. Our 2018 research found there were no improvements in standards and protocols regarding service continuity, backups and disaster recovery by the provincial or federal governments. Indeed, our research found that the provincial government and the federal government (through the CRTC) deferred to the opinions of the Telco's. For example, the provincial government did not include specific required standards for systems back-up and recovery and did not enhance its 911 service continuity by mandating compliance to industry standards in its RFP for telecommunications services. Furthermore, the CRTC appeared to base its decisions primarily on the input from Telco's rather than seek an independent opinion. Clearly, since it was not in the financial interest of the Telco's to enhance their backup and recovery standards, it was the responsibility of government to enforce these standards.

Undoubtedly, the complex and overlapping regulatory and organizational structures of the various levels of governments as it relates to the provision and oversight of 911 service has contributed to the overall lack of more stringent requirements for adherence to internationally recognized industry standards. When there are multiple levels of governments involved in the provision of an essential service, this appears to contribute to a lack of accountability and ultimately learning for all key stakeholders.

Unfortunately, perhaps it takes a tragedy to effect change. Had a fatality occurred due to this 911 service outage, undoubtedly, the outcome would have been different. In the wake of a public outcry the federal government (through the CRTC) may have been motivated to investigate the incident to determine how such a significant telecommunications outage could have occurred and in particular the circumstances surrounding a lack of a backup system. It appears the lack of a tragedy did not create an impetus for the federal government or the CRTC to use its legislative authority to introduce a standard requiring systems backup at an alternate location. As evidenced from this incident, if the CRTC's standards had reflected the IEC industry standards, this incident would not have occurred. 
While the CRTC is responsible for ensuring service continuity, this does not diminish the responsibility of local governments to ensure 911 service continuity. As discussed earlier in the paper, the contractual arrangements between local governments and the various Telco's did not address 911 service continuity, back-up protocols or a reasonable service outage period as part of their respective contracts with their respective telecommunications providers.

Despite a number of changes in responsibility for telecommunications and 911 services that have occurred at the provincial level, these changes appear to be driven by the desire for administrative efficiency and cost effectiveness rather than to address the possibility of service continuity. It is also disappointing that the Federal government agency (CRTC), which has ultimate regulatory authority for 911 service delivery, has appeared to abdicate its responsibility to the Telco's as illustrated through the decision it made as a result of its 2015 consultation process. As is evident from the recent (2018 and 2019) airline Boeing 737 crashes, the American Federal Aviation Authority (FAA) appeared to allow the aircraft manufacturers to set standards and perform their own testing and revision. Clearly, this did not result in a sufficient level of oversight and adherence to standards.

This research has added to the literature on telecommunications and how organizations respond to near misses. It expands the research by examining the roles and standards of the wide array of organizations that are involved in emergency preparedness. There is a wide scope for further research on this topic. In particular, it would be beneficial to follow these organizations on a longitudinal basis to discern if this was really a wake-up call and that it had a significant impact on telecommunications protocols as it relates to emergency preparedness.

\section{REFERENCES}

Baker, M.C., Witschorik, C.A., Tuch, J.C., Hagey-Espie, W., \& Mendiratta, V.B. (2004). Architectures and disaster recovery strategies for survivable telecommunications services. Bell Labs Technical Journal, 9(2), 125-145.

Carroll, J.S. (1998). Organizational learning activities in high-hazard industries: The logics underlying self analysis. Journal of Management Studies, 35(6), 699-717.

CRTC. (2015). Notice of Consultation, CRTC 2015-305. Retrieved August 1, 2028, from https://crtc.gc.ca/eng/archive/2015/2015-305.htm

Department of Canadian Heritage. (2007). Retrieved August 9, 2007, from www.canadianheritage.gc.ca/pc-ch/ac-os/index_e.cfm

Franklin, M. (2019, August 16). Telus customers' blood boiling after two days of email outage. Retrieved from https://calgary.ctvnews.ca/telus-customers-blood-boiling-after-two-days-of-email-outage1.4553130

Furey, M.A. (2011). Employee responsibility and virtuality during crisis decision-making. [Doctoral dissertation, University of Strathclyde].

Jolera. (2013, October 10). Rogers apologizes for country-wide wireless outage, gives customers one day of free service. Retrieved from http://business.financialpost.com/technology/rogers-apologizesfor-country-wide-wireless-outage-gives-customers-one-day-of-free-service

Madsen, P.M. (2009). These lives will not be lost in vain: Organizational learning from disaster in US coal mining. Organization Science, 20(5), 861-875.

McMillan, E. (2017, August 4). Bell, Telus service restored in Atlantic Canada. Retrieved from https://www.cbc.ca/news/canada/nova-scotia/bell-telus-phone-service-atlantic-provinces1.4235224

Memorandum of Understanding Between the Canadian Radio-television and Telecommunications Commission and The Body of European Regulators for Electronic Communications. (2018, October). Retrieved form https://crtc.gc.ca/eng/internet/berec.htm

Morris, M.W., \& Moore, P.C. (2000). The lessons we (don't) learn: Counterfactual thinking and organizational accountability after a close call. Administrative Science Quarterly, 45(4), 737-765. 
Nunatsiaq News. (2011, October 7). Northern telcom service restored after 16-hour Telesat Canada satellite glitch. Retrieved from https://nunatsiaq.com/stories/article/65674telesat_canada_screw_ up_knocks_out_northern_telco ms

O’Neil, L. (2019, July 7). Massive Rogers wireless outage causes total chaos in Toronto. Retrieved from https://www.blogto.com/tech/2019/07/massive-rogers-wireless-outage

Power, B. (2014). Basic 911 Service Enhances Safety for Residents. Retrieved from https://www.releases.gov.nl.ca/releases/2014/just/1215n08.aspx

Rixon, D., \& Furey, M. (2011). Oversight of telecommunications regulatory agencies. International Journal of Internet Technology and Secured Transactions, 3(3), 223-239.

Rixon, D., \& Furey, M. (2009, February), Fire on the Line: A Stakeholder Analysis of a Bell Aliant Telecommunications Service Outage. Workplace Review, pp. 13-2.

Federal Communications Commission. (2020). What we do. Retrieved from https://www.fcc.gov/aboutfcc/what-we-do

Australian Communications and Media Authority. (2020). Who we are. Retrieved from https://www.acma.gov.au/who-we-are

Yin, R.K. (1994). Case Study Research: Design and Methods (2nd Edition). Applied Social Research Methods, 5, Sage, London.

\section{APPENDIX}

\begin{tabular}{|c|c|c|c|c|}
\hline Reference/year & Service Provider & $\begin{array}{l}\text { Service } \\
\text { Disruption }\end{array}$ & $\begin{array}{l}\text { Duration of } \\
\text { Interruption }\end{array}$ & Location \\
\hline (Franklin, 2019) & Telus & Telus.net email & $3+$ days & Western Canada \\
\hline (O’Neil, 2019) & $\begin{array}{l}\text { Rogers, } \\
\text { Freedom Mobile }\end{array}$ & $\begin{array}{l}\text { Voice services } \\
\text { and } 911\end{array}$ & $1+$ day & Toronto \\
\hline (McMillan, 2017) & Bell and Telus & $\begin{array}{l}\text { internet, TV, wireless } \\
\text { and landline phones, } \\
\text { including some } \\
911 \text { services }\end{array}$ & 4 hours & $\begin{array}{l}\text { Atlantic Canada (4 } \\
\text { provinces) }\end{array}$ \\
\hline (Jolera, 2013) & Rogers & $\begin{array}{l}\text { Voice and text } \\
\text { messaging }\end{array}$ & 5 hours $(5.05)$ & National \\
\hline $\begin{array}{l}\text { ("Northern telcom } \\
\text { service...", 2011) }\end{array}$ & $\begin{array}{l}\text { Northern Telecom } \\
\text { Canada }\end{array}$ & $\begin{array}{l}\text { long distance } \\
\text { telephone, cellular, } \\
\text { internet, and } \\
\text { automated } \\
\text { banking services }\end{array}$ & 16 hours & Nunavut \\
\hline
\end{tabular}

